Lauren Scharff, U. S. AIR FORCE ACADEMY, laurenscharff@gmail.com John Draeger, SUNY BUFFALO STATE, draegejd@buffalostate.edu

Sarah Robinson, U. S. AIR FORCE ACADEMY, sarah.robinson@usafa.edu Leli Pedro, UNIVERSITY OF COLORADO - DENVER, leli.pedro@cuanschutz.edu Charity Peak, ASSOCIATION OF COLLEGE AND UNIVERSITY EDUCATORS, charityspeak@gmail.com

\title{
Developing Metacognitive Instructors Through a Guided Journal
}

\section{ABSTRACT}

Metacognitive instructors incorporate awareness and timely self-regulation in their teaching practice to support their current students' learning. This exploratory study, using mixed methods, gathered empirical data to extend the work on student metacognition by documenting teacher experiences with metacognitive instruction, the impact of instructor use of a guided journal on the development of metacognitive instruction practices, and students' perceptions of instructor responsiveness to their learning and engagement. Journal Intervention $(\mathrm{N}=40)$ and Control $(\mathrm{N}=33)$ instructors from five institutions and their students $(N=796)$ responded to multiple questionnaires throughout a semester. Data revealed significantly more baseline familiarity with and engagement in reflective teaching than metacognitive instruction for both groups. Within the Intervention group, qualitative data consistently suggested a positive impact from engagement with the journal, especially with respect to an increased focus on learning objectives and student engagement (rather than on content coverage) in pre-lesson planning, and on being aware of how students were achieving the learning objectives. Significant positive correlations were found between instructor use of the journal and student ratings of instructor responsiveness to their learning and engagement, and instructor use of effective instructional practices. Although instructors were enthusiastic overall about using the journal and incorporating metacognitive instruction, they did report barriers including time, existing habits, and uncertainty about alternate instructional practices. Based on our findings, we share strategies for using our journal prompts as a tool to facilitate faculty development of metacognitive instruction.

\section{KEYWORDS}

metacognition, metacognitive instruction, metacognitive teaching, faculty development

\section{INTRODUCTION}

This study investigated instructor experiences with metacognitive instruction, rather than student experiences with metacognitive learning. Studies on student metacognition commonly focus on developing student abilities to metacognitively implement effective learning strategies, resulting in 
customized choices for success in different learning situations. Our study focused on ways to develop instructor abilities, specifically through use of a guided journal, to metacognitively implement effective teaching practices resulting in timely, customized choices to support the success of different groups of students.

Often metacognition is simplified as "thinking about thinking," and this catchy phrase is attributed to Flavell (1976). While this phrase captures the critical "awareness" component of metacognition, Flavell's definition of metacognition also includes a "self-regulation" component where actions and choices are made in response to what is learned from awareness: “... active monitoring and consequent regulation and orchestration of these processes in relation to the cognitive objects or data on which they bear, usually in the service of some concrete goal or objective" (Flavell 1976, 232). It is this latter, more complete description of metacognition as the combination of awareness and self-regulation that grounded our inquiry.

More specifically, we use the term "metacognitive instructors" to describe instructors who incorporate awareness and timely self-regulation in their teaching practice to support their current students' engagement and achievement of learning objectives. The implementation of these awareness and self-regulation activities are informed by the tenets of good teaching such as being learner-focused and evidence-based (Ambrose et al. 2010; Bain 2004; Davis and Arend 2012; NRC 2000). If we consider how a metacognitive student reacts to doing poorly on a test, they reflect on their study strategies (awareness) and adjust their study strategies to improve their test taking in their current class (timely-self regulation). Being metacognitive helps this student avoid continuing to use the same ineffective study strategy or waiting to make changes until the next semester/course, both of which negatively impact their success in their current course. The parallel example for metacognitive instructors is that when a lesson is going poorly (low student engagement or achievement of the learning objectives), instructors reflect on their instructional strategies (awareness) and adjust their instructional strategies for their current students (timely self-regulation). While metacognitive instruction has a role in all aspects of teaching, this study focuses specifically on metacognitive instruction in lesson planning and execution.

Garrison, Anderson, and Archer (2000) frame an educational experience as a Community of Inquiry where learning is a function of three elements: social presence, cognitive presence, and teaching presence. In this learner-centered framework, metacognitive instruction aligns with the "teaching presence" element defined as the design and facilitation of the educational experience. Metacognitive instruction enables instructors to effectively customize course design (content, learning experiences, etc.) and facilitate learning experiences in response to their current students or classroom context. While metacognitive instruction focuses on the instructor role, it is still in service to a learning-focused classroom for "teaching presence is a means to an end-to support and enhance social and cognitive presence for the purpose of realizing educational outcomes" (Garrison, Anderson, and Archer 2000, 90).

For this project, we took the stance that metacognitive instruction could be a developable skill, just like metacognitive learning for students. Thus, we empirically investigated how the systematic use of a guided journal might impact both student perceptions of instructors' ability to engage them and support their achievement of learning objectives, as well as instructors' self-perceptions of their teaching. While there are many questions remaining to be investigated, we believe this initial study provides 
evidence that efforts to develop metacognitive instruction are valuable and should be encouraged, and that our journal prompts are a potential faculty development tool by which to do so.

\section{Background}

Previous research suggests metacognition helps students become better learners. Many studies have shown the beneficial impacts of metacognition for learners in terms of study skills and exam performance, reading and writing ability, and scientific understanding (Dabarera, Renandya, and Zhang 2014; Isaacson and Fujita 2006; Leopold and Leutner 2015; Mynlieff et al. 2014; Negretti 2012; Thiede, Anderson, and Therriault 2003). One of the common tools shown to effectively develop metacognition (specifically the awareness component) is reflection, often through reflective writing (McAlpine et al. 1999; Schraw 1998; Tanner 2012). This intentional development of awareness through reflection can also support student self-regulation (the second component of Flavell's definition of metacognition) where learners make changes informed by their awareness (Dunlosky and Theide 2013; Huber and Hutchings 2004). These student-focused studies support the use of reflective writing to develop metacognition (both awareness and self-regulation).

Instructor-focused studies have similarly recognized reflection is a key technique for instructors to increase their awareness of their practice. Teacher preparation programs have long promoted reflective practice as an essential component (e.g., Grossman 2008; Ward and McCotter 2004), and the scholarly teaching tradition in higher education relies on reflection of both instructional practices and personal assumptions to improve teaching (Brookfield 2017; Hutchings and Shulman 1999; Palmer 2007; Richlin 2001). Such reflective teaching can be developed in several ways, including lesson study, video analysis, and topical discussions, but, in parallel with the student-focused studies, journal writing is a common method (e.g., Bain et al. 2002). Journals provide visibility to the teacher's process of analyzing teaching (Risko, Roskos, and Vukelich 2002), and encourage teachers to critically examine practical teaching experiences (Lee 2008). Journals also help teachers express views and challenge traditions within the profession (Good and Whang 2002). Furthermore, structured reflection, such as a guided journal, promotes the ability to develop professionally based on personal strengths and goals (Korthagen and Vasalos 2006).

However, while reflective teaching leads to awareness, that alone is insufficient to describe metacognition. To be metacognitive, an instructor must also display self-regulation in which individuals use their awareness to adjust their behaviors in ways more likely to lead to success (Flavell 1976). In fact, Kreber (2002) noted that expert teachers engage in both reflective self-monitoring (ongoing selfawareness) and self-regulation. Many of the perspectives related to reflective teaching (also known as reflective practice), also suggest pausing after teaching to improve future instruction. Kolb's (2014) reflective cycle is a commonly used model for this reflection-on-action context (Schön 1987), whereby teachers consciously return to their experiences in the classroom, reevaluate those experiences, decide what could be done differently, and then plan for a new action in the future. This cycle supports important continuous improvement in teaching practice that benefits future students.

The bridge from reflective teaching to metacognitive instruction is to shift the focus from future students to our current students by making timely changes (self-regulation) based on the reflection developed through tools such as a journal (awareness). This puts instructors in the realm of reflection-in- 
action rather than reflection-on-action, requiring instructors to consider changes to "what we are doing while we are doing it" (Schön 1987, 26). In the context of metacognitive instruction, timely selfregulation requires that instructors leverage their awareness (e.g., of their instructional choices, of the current physical context and emotional climate, and of their students' engagement and learning) to adapt their instruction to their current group of students. This may require instructors to adjust their established lesson plans and employ alternative, evidence-based instruction practices. Timely adjustments can occur both during that lesson and/or when planning for subsequent lessons for that group of students. A journal can support both the reflection and self-regulation aspects of reflection-onaction by using prompts that ask instructors to brainstorm/plan what actions they will take if they become aware that the lesson is just not working.

Despite many parallels between metacognitive students and metacognitive instructors (e.g., Scharff and Draeger 2015), much less research in higher education has focused on documenting instructors' use of metacognitive instruction practices in comparison to the literature on student metacognitive learning practices. Similarly, while much research has documented that student engagement in metacognitive learning practices typically requires some directed development (e.g., Case and Gunstone 2002; Hogan et al. 2015), little research has empirically investigated the effectiveness of interventions to develop metacognitive instruction practices. While metacognitive instruction has broad applications across all aspects of teaching, this study focused specifically on how instructors could enhance student engagement and achievement of learning objectives. Thus, this study extends previous work about student metacognition by focusing on metacognitive instruction and gathering empirical data about how the use of a semester-long guided journal impacts the development of metacognitive instruction. The journal encourages metacognition (both awareness and timely selfregulation) by prompting instructors to engage in reflection on the specific aspects of student engagement and achievement of the learning objectives, and to consider making timely adjustments using alternate, evidence-based instruction strategies.

\section{Purpose}

This study had three main goals, each of which led to several research questions and hypotheses. Our first goal was to establish a baseline understanding of instructors' familiarity with and use of metacognitive instruction in comparison to reflective teaching, and whether these practices were related to the number of years of teaching experience. Based on the minimal amount of published work on metacognitive instruction compared to the large body of published work documenting the value of reflective teaching, we hypothesized instructors would be more familiar with reflective teaching. However, once given definitions of each practice, instructors may believe they practice metacognitive instruction. Our work is exploratory with respect to the relationship between the number of years teaching and engagement in metacognitive instruction and in reflective teaching.

Our second goal was to empirically investigate the impact of instructor participation in a semester-long guided journal intervention on developing metacognitive instruction, measuring a) three specific instructor self-reported behaviors of pre-lesson planning, in-class awareness, and consideration of timely adjustments; b) instructor perceptions of their confidence and comfort related to metacognitive instruction; and c) student perceptions of instructor responsiveness to their achievement 
of the learning objectives and engagement. We hypothesized the more the instructors used the guided journal, the more they would engage in metacognitive instruction and the better they would feel about their teaching (e.g., perceptions of increased confidence in their classroom and in their ability to help their students achieve their learning outcomes). We also hypothesized the more the instructors used the guided journal, the more students would report instructor responsiveness to their learning and engagement.

Our third goal was to better understand motivations and deterrents to instructor engagement in metacognitive instruction. Based on our personal observations, we expected time constraints and a pressure to cover content might be strong deterrents, but otherwise these questions were exploratory.

\section{METHODS}

\section{Participants}

At the start of the study, 73 instructors from five public, United States higher education institutions volunteered to participate based on general solicitation emails sent to faculty who were engaged in or demonstrated interest in faculty development activities. These faculty either self-selected (the majority) or were placed into the Intervention or Control groups. Intervention and Control group participation from each institution included: SUNY Buffalo State (14 Intervention, 13 Control); Kent State (nine Intervention, six Control); Auburn University at Montgomery (two Intervention, two Control); University of Colorado Denver College of Nursing (three Intervention, four Control); U. S. Air Force Academy (12 Intervention, eight Control). Courses for both groups represented a wide variety of disciplines across the social sciences (e.g., political science, psychology, anthropology), humanities (e.g., foreign languages, English, history), math and sciences (e.g., algebra, physics, biology), and integrated studies (e.g., engineering, dance, nursing). Participating instructors (both Intervention and Control) could choose to participate with a single section/course or with multiple sections/courses. All portions of data collection (multiple instructor and student questionnaires) were voluntary and participation was not consistent across instructors. There was no compensation given for participation by faculty in either group.

For those who completed the pre-semester questionnaire that gathered teaching experience $(\mathrm{N}$ $=68$ ), instructors were generally well-balanced in terms of years of experience teaching: for Intervention and Control, respectively, there were seven and eight who had less than five years of teaching experience; nine and 10 who had 5-9 years of experience, eight and five who had 10-15 years of experience, and 12 and nine who had 16+ years of experience. Both groups were also well-balanced with respect to reported motivations to participate in the study. The majority of participants in both groups reported wanting to improve their teaching and/or student success, with fewer but roughly equal numbers mentioned providing support for the study and/or advance the profession, and an even smaller number in each group mentioning innate curiosity. A total of 443 students from Intervention instructors and 353 students from Control instructors participated in at least one of the student questionnaires. For each group, these students represented an even spread of first-year through senior-level students, with a small number of graduate students. 


\section{Procedure and materials}

All procedures were approved by an institutional ethics review board. As part of their metacognitive instruction practice, Intervention instructors were asked to respond to a series of guided journal prompts that encouraged metacognitive instruction in support of student engagement and achievement of learning objectives (see table 1). The prompts were framed in terms of familiar lesson planning elements, but were designed around the activities of metacognitive awareness and selfregulation.

- Pre-lesson planning prompts. These prompts requested identification of the learning goals for that lesson; an intended evidence-based, instructional practice for the lesson; the means by which to assess student engagement and learning; likely challenges that might be encountered; and alternative instructional practices to use if needed.

- Metacognitive instruction alignment. These pre-planning prompts in essence ask the instructor to a) identify the specific target of their awareness, b) determine how they will achieve that awareness, and c) pre-plan self-regulation options in response to that awareness.

- In-class prompts. These prompts collected observations of success (or not) of student engagement and learning, observations of the challenges being encountered, and consideration of possible timely adjustments.

- Metacognitive instruction alignment. These in-class prompts focused on helping the instructors document how the awareness/self-regulation plan from the pre-lesson prompts actually played out during class.

- Post-lesson prompts. These prompts asked instructors to summarize what worked well and how they knew what worked, what challenges they perceived compared to what they predicted, what changes they might plan to make in a subsequent lesson, and identification of possible resources they might access to learn about additional alternative instructional practices.

- Metacognitive instruction alignment. These post-lesson prompts encouraged analysis of how their plan (pre-lesson prompts) matched the reality (in-class prompts) and how that analysis may improve their metacognitive instruction in the future.

Instructors were encouraged to document these reflections in a written journal (with reflections on in-class awareness to be written after the lesson). The use of a journal to record the reflections is aligned with the tenets of best practices, making the reflections more explicit and accessible for later reflection (Boyd and Boyd 2005). These reflective journal prompts were designed to encourage instructors to engage in awareness and timely self-regulation that benefitted current students. Complete sentences and full prose answers were not required for the journal, and instructors were informed they would not be required to submit their journals for review - a deliberate, methodological choice. By not 
collecting the journals, we placed the focus on journals being a tool for the instructor's teaching practice, rather than placing demand characteristics on the faculty and risking the journals being written for the investigators. The goal of the study was not the content of the journal, but the engagement with the process to develop awareness and support self-regulation. In contrast, Control instructors taught their courses as usual without use of this journal, although they might have had their own ways of reflection that they used independent of this study. Instructors and students in the Intervention and Control groups completed questionnaires that were used to gauge the efficacy of these practices on the goals of learner engagement and achievement of the learning objectives.

Table 1. Metacognitive journal intervention: guided reflection questions

\begin{tabular}{|c|c|}
\hline Activities & Questions \\
\hline Planning (pre-lesson reflection) & $\begin{array}{l}\text { For this lesson, what is your content/skill } \\
\text { learning objective(s)? } \\
\text { - What are your intended strategies during the } \\
\text { lesson to engage students to achieve this primary } \\
\text { objective(s)? Why? } \\
\text { - How are you planning to assess student } \\
\text { engagement with and achievement of your } \\
\text { lesson objective(s) during the lesson? } \\
\text { - What do you believe will be your biggest } \\
\text { challenge during this lesson? } \\
\text { - What are your alternative strategies to use } \\
\text { during the lesson? }\end{array}$ \\
\hline $\begin{array}{l}\text { In-class awareness } \\
\text { (reflection during class) }\end{array}$ & $\begin{array}{l}\text { What am I observing that tells me whether or } \\
\text { not students are achieving my primary } \\
\text { content/skill learning objective(s)? } \\
\text { - If I observe something is not working, how can I } \\
\text { modify my approach? } \\
\text { - What is the biggest challenge that I am } \\
\text { encountering during class? }\end{array}$ \\
\hline $\begin{array}{l}\text { Lessons learned/planned revisions for } \\
\text { future lessons (post-lesson reflection) }\end{array}$ & $\begin{array}{l}\text { What strategies worked well? What is your } \\
\text { evidence for their success? } \\
\text { Did your actual biggest challenge match with } \\
\text { your prediction before class? Explain. } \\
\text { - What changes do you plan to make when } \\
\text { teaching this content/skill goal in the future? } \\
\text { Why? } \\
\text { How might you learn about additional alternate } \\
\text { strategies to teach this content/skill goal (e.g., } \\
\text { consult literature, talk with other instructors, } \\
\text { attend workshops)? }\end{array}$ \\
\hline
\end{tabular}


Multiple online questionnaires, with a mixture of closed-ended and open-ended questions, were used to investigate the three research goals. The timing and content varied somewhat by whether the instructor was an Intervention instructor (using the guided journal) or a Control instructor. Both groups of instructors received the same pre-semester questionnaire that included both demographic and research questions. Only the Intervention group received a mid-semester questionnaire, while both groups each received their own post-semester questionnaires. Students in both the Intervention and Control instructors' courses were given the same mid- and post-semester questionnaires, and they had no awareness of the study's design, to which group their instructor belonged, or their instructor's level of use of the journal.

The pre-semester questionnaire included demographic questions (name, course, years of teaching experience) and questions to help us answer Goal One and the Goal Three baseline questions posed in the Purpose section above. In the pre-semester questionnaire, instructors were first given clear definitions of reflective teaching and metacognitive instruction. The instructors then answered questions about their familiarity with (open-ended) and engagement with (using 6-point scales) both metacognitive instruction and reflective teaching. Word anchors for each point on the scale were: never, rarely, occasionally for at least one class, frequently for at least one class, frequently for some of my classes, and frequently for all of my classes. Next, instructors rated (using 10-point scales) the frequency of their engagement in the pre-lesson planning, in-class awareness, and consideration of timely adjustments as described in the journal prompts (our three targeted metacognitive instruction practices). Value anchors were given so that $1=$ no lessons, $5=\sim$ half the lessons, and $10=$ every lesson. They also rated (using 10-point scales) their confidence in their ability to help students engage with and achieve their planned lesson learning outcomes and their comfort in allowing the flow of the lesson to be adjusted based on their in-class awareness of student achievement of the learning outcomes and engagement. Value anchors were given so that $1=$ no confidence/comfort and $10=$ extremely confident/comfortable. Finally, the questionnaire asked respondents to indicate (from a list of nine options including "other") what behaviors they might or might not engage in when they perceived it to be necessary to make timely adjustments to their instruction based on their awareness of student achievement of learning objectives and engagement. Possible options included making no change due to being uncomfortable, not having time or other constraints, or not being sure of an alternative strategy. Other options included making a change if it were convenient, if the instructor was comfortable with the material, or if there were pre-planned alternative strategies.

The mid-semester questionnaire for Intervention instructors was given approximately halfway through the semester. It included a question asking about the frequency of their use of the journal on a five-point scale (never, rarely, occasional lessons, most lessons, every lesson). Instructors were also asked open-ended questions about how the use of the journal impacted their awareness of their lesson planning and student success, about their biggest challenges in implementing metacognitive instruction, and their current motivations for incorporating metacognitive instruction.

The post-semester questions for Intervention instructors included those from the pre- and the mid-semester questionnaire, plus questions asking instructors to reflect on the impact of engaging in metacognitive instruction as described in the journal and if they planned to continue using 
metacognitive instruction and why. The post-semester questions for Control instructors asked the same questions as the Intervention instructors except questions about the use of the guided journal.

Each of these pre-, mid- and post-questionnaires took 10-15 minutes to complete. Although not required for ethics board approval, participating instructors were provided an informed assent form that explained the expectations of participation and included contact information for the investigators. It also explained their participation was completely voluntary and they could discontinue participation at any time without penalty.

Both Intervention and Control instructors asked their students to complete mid- and postsemester questionnaires as well. These questionnaires asked students to answer four sets of three questions that were designed to capture the impact of metacognitive instruction their teachers were practicing in their classrooms on the students' learning experiences. The four sets of questions asked for ratings (10-point scales) of 1) instructor responsiveness to student achievement of learning objectives, 2) instructor use of instructional techniques that enhanced learning, 3) instructor responsiveness to student engagement, and 4) instructor use of techniques that enhanced engagement. Each set first asked about their instructors' responsiveness to them as individual students, then to the class as a whole, and then provided space to explain their responses. Students had approximately five minutes of class time to complete the online questionnaires. They were informed participation was not required and there was no penalty for non-participation. Because students did not know if their instructors participated in the Control or Intervention group, and because there were multiple institutions, instructors, and courses for each of the two groups, we believe these student data provide a valid external assessment of instructor behaviors as they relate to supporting student engagement and learning.

\section{RESULTS}

A series of analyses were performed, first for the instructor data and then for the student data. The different Ns for each analysis reflect that some participants left individual questions blank on one or more of their questionnaires. Of the 40 instructors in the Intervention group, 36 submitted the presemester questionnaire, 28 submitted the mid-semester questionnaire, and 30 submitted the postsemester questionnaire. Of the 33 instructors who signed up for the Control group, 30 completed the pre-semester questionnaire and 20 completed the post-semester questionnaire. Prior to analyses, instructor data were linked to their student data; however, not all instructors had their students complete the mid- and post-semester questionnaires: 30 Intervention instructors had students who completed the mid-semester questionnaires $(N=442), 27$ Intervention instructors had students who completed the post-semester questionnaires $(N=304), 21$ Control instructors had students who completed the mid-semester questionnaires $(N=353)$, and 20 Control instructors had students who completed the post-semester questionnaires $(N=260)$.

Analysis of the quantitative data included correlations and ANOVAs. Content analysis of each of the qualitative open-ended questions involved the following steps: 1) at least two investigators separately reviewed responses to determine thematic categories, 2) these individuals discussed and finalized categories, 3 ) the investigators separately coded the responses, and 4) they compared, discussed, and adjusted coding to ensure inter-rater reliability. In all cases for qualitative data reported in 
this paper, the differences between the coding were not greater than 11 percent, with the majority showing five percent or less discrepancy.

\section{Goal one: Familiarity with metacognitive instruction}

To establish a baseline understanding of familiarity with and engagement in metacognitive instruction and reflective teaching, we performed several quantitative and qualitative analyses. $T$-tests analyzing the quantitative responses for the Intervention and Control groups (rating-scale data) allowed us to test for selection bias for the two groups with respect to several factors. The results indicated Intervention and Control groups were not significantly different at the beginning of the semester with respect to the number of years of teaching, $t(65)=-0.26, p=.80$. Using the scale, $6=$ frequently for all my classes; 5 = frequently for some of my classes; 4 = frequently for at least one class; $3=$ occasionally for at least one class; 2 = rarely; $1=$ never, no differences were found between the Intervention and Control groups in prior engagement with metacognitive instruction; $t(65)=0.42, p=.68$, or in prior engagement with reflective teaching, $t(65)=.02, p=.99$. Intervention and Control groups, respectively, had means of 3.9 and 3.7 (approaching frequent engagement for at least one class) for prior engagement with metacognitive instruction and means of 5.2 and 5.2 (frequent engagement for some-to-all of my classes) for prior engagement with reflective teaching. Not surprisingly, for both groups combined, the difference in self-reported engagement in reflective teaching and metacognitive instruction was significant, $t(66)=5.78, p<.001$, with greater prior engagement in reflective teaching. There was no correlation between the number of years of teaching and engagement with either metacognitive instruction, $r_{s}(65)=0.01$ or reflective teaching, $r_{s}(65)=0.09$. However, there was a significant correlation between the two practices, $r_{s}(65)=0.27, p<.03$.

The qualitative data gave us further insights into the quantitative results above. Both Intervention and Control groups began the study reporting similar, but widely ranging levels, of familiarity and understanding of metacognitive instruction. Approximately one third of each group reported being familiar with metacognitive instruction, while approximately one fifth of the Intervention instructors and one quarter of the Control group instructors reported no familiarity at all. The remaining instructors in each group reported a vague understanding of metacognitive instruction. For example, one instructor reported, "[I have a] general idea of it, but not specifically related to teaching," and another responded,

$\mathrm{Hmm}$, I was not familiar with the name; I have heard of it, but was never instructed in it. However, I do think about courses and teaching in that way. So I do it, perhaps inconsistently or partially, without knowing that's what I was doing.

When asked to describe specific metacognitive instruction practices that they might use, the majority (approximately two-thirds) of responses in both groups included very general reflections on awareness, whereas far fewer reported combining awareness with timely self-regulation using specific evidence-based strategies to modify their instruction. For example, 
Assessing my feelings after a lesson-did I enjoy the class, did I feel as though I was a good clear window through which students could see the wonder of the universe? Or did I get in the way? What could I do differently?

Note such general reflections rarely diagnosed whether particular learning objectives were met. In addition, instructors focused on changes for the future rather than changes to benefit the current group of students. For example, one respondent pointed to strategies like "gathering of data on achievement of learning objectives, writing end-of-course reports ... and narration on suggested changes and improvements." Again, while some respondents were concerned with assessing the quality of learning in a generalized way, they did not report equating metacognitive instruction with the importance of intentionally making timely adjustments for their current group of students.

The remaining one-third of the respondents indicated some action related to in-class awareness of student engagement and achievement of the lesson learning outcomes. However, while some reported they considered making timely adjustments based on their observations, they were often not equipped with strategies to execute those intentions. For example, one respondent reported, "I am unaware of specific strategies, but I suppose it would be changing up the lesson as it was bombing as best I could." Another stated, "I consider students' nonverbal and verbal communication to gauge whether they are aligned with my lesson objectives. If they seem disengaged or uninterested, I may switch gears to another topic that is more salient to them." And, "I have an internal radar for when I have talked too long and the students are getting bored. That is when I adjust and try to get them actively involved." Overall, the responses indicated instructors from both the Intervention and Control groups discussed metacognitive instruction in similar ways. While both groups tended to be reflective about their teaching, neither group was particularly focused on the importance of making timely adjustments as called for in metacognitive instruction.

\section{Goal two: Impact of journal intervention Instructor data}

Our second goal was to investigate the impact of participation in a semester-long journal intervention as self-reported by instructors regarding their perceptions of the development of metacognitive instructional practices, and by students regarding their perceptions of instructor responsiveness to their learning and engagement. We analyzed both scale-response data and the openended responses. For the instructors' scale-response data, there were 27 Intervention group instructors and 18 Control group instructors who completed both the pre- and the post-questionnaires so we could analyze time as a within-groups factor. Because the Intervention group instructors reported a wide range of engagement with the journal, we divided the group into two subgroups: Good Journal Use and Insufficient Journal Use. Intervention instructors were placed in the Good Journal Use group $(N=21)$ if they indicated on their questionnaires that they engaged in journal use "occasionally" $(N=12)$, "most lessons" $(N=6)$ or "every lesson" $(N=3)$. Those who indicated engagement levels of "rarely" $(N=2)$ or "never" $(N=2)$ were placed in the Insufficient Use group $(N=4) .{ }^{1}$ Because of the small subgroup sample sizes, we combined the first three levels into Journal Use for analysis, and we did not include the Insufficient Use group in the instructor ANOVAs. 
To analyze the impact of the journal intervention on instructor self-reported engagement in the three targeted metacognitive instruction practices (pre-lesson planning, in-class awareness, and consideration of timely adjustments), we performed a 3 (Practice) x 2 (Time) x 2 (Group: Good Journal Use vs. Control) mixed ANOVA with both practice and time being within variables. ${ }^{2}$ See figure 1 for means for each condition, all of which indicate fairly high levels of engagement. The analysis yielded a significant main effect of Practice with a large effect size, $F(2,64)=15.99, p<.01, \eta_{\mathrm{p}}{ }^{2}=0.33$. On a scale from 1 ("no lessons") to 10 ("every lesson"), instructors in both groups were more likely to engage in pre-lesson planning $(M=8.85)$ than in in-class awareness $(M=7.96)$, or consideration of timely adjustments $(M=7.42)$. A significant Time $\mathrm{x}$ Practice interaction moderated that main effect, also with a large effect size, $F(2,64)=21.69, p<.01, \eta_{\mathrm{p}}{ }^{2}=0.40$. As the figure 1 graphs illustrate, both groups indicated a drop in pre-lesson planning across the semester, while there were some increases in in-class awareness and the consideration of timely adjustments, especially for the Journal Use group. Thus, the differences between the engagement in the three practices were decreased by the end of the semester. There was no main effect of group, nor any significant interactions pertaining to group.

Figure 1. Group means and standard errors for the three instructor self-reported metacognitive practices (pre-lesson planning, in-class awareness, and consideration of timely adjustments) at both the beginning and the end of the semester

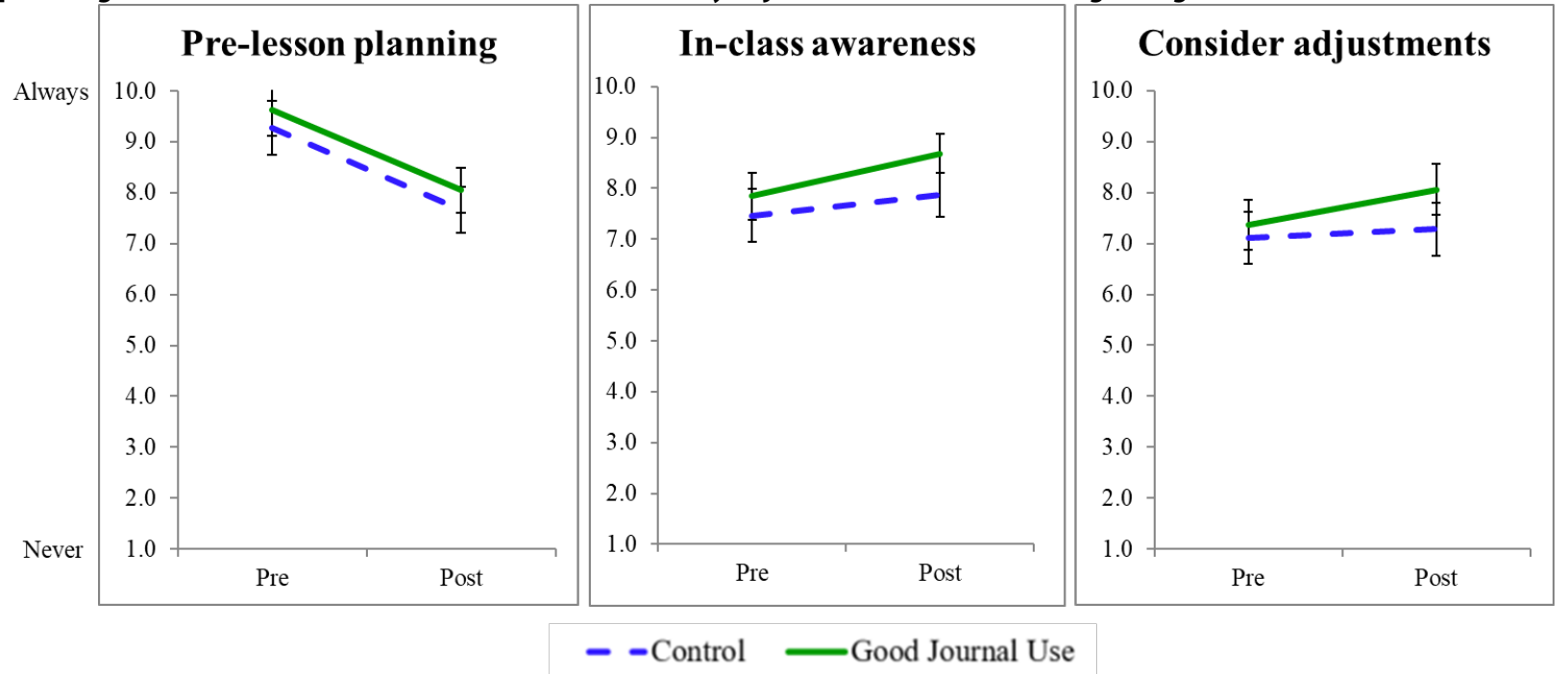

Overall, instructors in both groups were significantly more likely to engage in pre-lesson planning, but this decreased over time and engagement in the other practices increased, especially for the Good Journal Use group (significant time x practice interaction).

To analyze the impact of the journal intervention on 1) instructor self-reported confidence in their ability to help students engage with and achieve their learning outcome ( $1=$ no confidence and 10 = extreme confidence) and 2) instructor self-reported sense of comfort in allowing the flow of the lesson to be adjusted by student achievement of learning outcomes and engagement ( $1=$ not comfortable and 10 = extremely comfortable), we performed two separate 2 (Group) x 2 (Time) mixed ANOVAs. Figure 2 shows means of all conditions, all of which again indicate fairly high levels of confidence and comfort. There were no significant main effects or interaction for confidence in ability in achieving learning 
outcomes. However, for the comfort in adjusting the lesson, there was a significant main effect for Group, $F(1,32)=4.0, p=.05, \eta_{\mathrm{p}}^{2}=0.11$, with the Good Journal Use group indicating more comfort.

Figure 2. Group means and standard errors across time for instructors' self-reported confidence in their ability to help students engage with and achieve their learning outcome (LO) (left graph) and instructors' self-reported sense of comfort in allowing the flow of the lesson to be adjusted by student engagement with and achievement of their learning outcomes (right graph)



Overall, the Good Journal Use group reported significantly more comfort than the Control group, but there were no significant differences in levels of confidence.

Qualitative data suggested journal use impacted Intervention group instructor awareness in ways not captured by the scaled-response questions as seen in figure 1. Approximately two-thirds of instructors who used the journal reported the use of metacognitive instruction practices increased their overall awareness of lesson objectives and student engagement in pre-lesson planning. For example, one instructor shared, "The strategies provide good guidance to help channel some of my thoughts and also provide a useful mechanism to ensure I am tying my plans to objectives [and] maintain alignment between course outcomes and guided learning." Several teachers commented on how using metacognitive instruction practices directed their attention toward student engagement: "I think it has caused me to focus less on information delivery and more on promoting student engagement."

Along with the increased focus on lesson planning intentions, almost half of instructors who used the journal reported increased in-class awareness of their students' achievement of learning objectives. For example, one instructor reported "use of metacognitive strategies has made me think a lot more about what constitutes student success." Another instructor shared, "I have become more aware of the evidence that learning is occurring or not occurring," and "I am more aware of my observations during class and how I respond to these inputs.” In summary, the qualitative data seem to reveal an impact on the way instructors engaged with the metacognitive instruction practices that was not seen in 
the quantitative data that simply measured the frequency of engagement (figure 1). Specifically, Intervention instructors reported using the journal increased overall awareness of pre-lesson planning intentions and in-class awareness of student achievement of the learning objectives.

\section{Student data}

Analysis of student data allowed for investigation of the impact of instructor use of the journal on student perceptions of how their instructors supported their own, and the overall class', learning and engagement. First, for all students whose instructors were in the Intervention group, we performed correlations to determine whether or not, at both mid-semester and at the end of the semester, the level of instructor self-reported journal use related to student perceptions. For each point in time, there were multiple instructors who reported each of the five levels of engagement with the journal and who also collected student feedback. The majority of instructors at both times reported occasionally or frequently using the journals; however, five instructors at mid-semester and four instructors at the end of the semester reported never or rarely using the journals, and three instructors at mid-semester and two instructors at the end of the semester reported journal use for every lesson. Second, we performed ANOVAs to compare student perceptions based on two groupings of students: those whose instructors were in the Good Journal Use group (Occasional, Frequent, Every Lesson) and those whose instructors were in the Control group.

For the correlation analyses, we included self-ratings of journal use for all Intervention instructors who completed their mid- or post-semester questionnaires and had their students complete their corresponding questionnaires. For the mid- and post-semester time periods, there were 21 and 23 Intervention instructors respectively whose self-ratings and student data were analyzed. However, they were not exactly the same group of instructors, so the total number of student participants varied across the time periods. Also, some students left some questions blank, so the number of students included in each specific correlation analysis also varied. Table 2 summarizes the Spearman correlation results at both mid- and post-semester between Intervention group instructor self-reported engagement with the journal and student perceptions for the eight questions regarding their instructor's responsiveness to and use of techniques to support learning and student engagement. It is important to point out that students were not aware of instructor levels of journal engagement. In all but one case the correlations were positive, with the majority achieving significance, indicating the more the Intervention instructors used the journal, the more favorably the students rated their instructors. 
Table 2. Intervention group: Spearman correlations between instructor engagement with journals and student perceptions of instructor

\begin{tabular}{|c|c|c|c|c|}
\hline Student questions & $\begin{array}{l}\text { Mid- } \\
\text { semester }\end{array}$ & $\begin{array}{l}\text { Student } \\
\mathrm{N}\end{array}$ & Post-semester & $\begin{array}{l}\text { Student } \\
\mathrm{N}\end{array}$ \\
\hline \multicolumn{5}{|l|}{ Instructor responsiveness } \\
\hline $\begin{array}{l}\text { Responsive to MY level of achievement } \\
\text { of learning objectives }\end{array}$ & $0.122^{*}$ & 285 & $0.139^{*}$ & 291 \\
\hline $\begin{array}{l}\text { Responsive to level of achievement of } \\
\text { learning objectives of class OVERALL }\end{array}$ & 0.087 & 285 & $0.154^{* *}$ & 292 \\
\hline $\begin{array}{l}\text { Responsive to MY level of engagement } \\
\text { during class }\end{array}$ & 0.099 & 275 & $0.130^{*}$ & 287 \\
\hline $\begin{array}{l}\text { Responsive to OVERALL level of } \\
\text { engagement during class }\end{array}$ & 0.112 & 277 & 0.094 & 287 \\
\hline \multicolumn{5}{|l|}{ Effective instructional techniques } \\
\hline $\begin{array}{l}\text { Used instructional techniques to } \\
\text { enhance MY learning }\end{array}$ & $0.134^{*}$ & 277 & $0.195^{* *}$ & 289 \\
\hline $\begin{array}{l}\text { Used instructional techniques to } \\
\text { enhance learning of class OVERALL }\end{array}$ & $0.141^{*}$ & 277 & $0.133^{*}$ & 287 \\
\hline $\begin{array}{l}\text { Used instructional techniques to } \\
\text { enhance MY level of engagement }\end{array}$ & $0.135^{*}$ & 276 & 0.098 & 280 \\
\hline $\begin{array}{l}\text { Used instructional techniques to } \\
\text { enhance OVERALL level of engagement } \\
\text { (Post only; see note) }\end{array}$ & No data & NA & -0.037 & 282 \\
\hline
\end{tabular}

Note: No data were collected at mid-semester for the final question regarding student perception of instructor use of techniques to enhance engagement of the class at large due to a coding error in the survey software.

${ }^{*} p \leq .05 .{ }^{* *} p \leq .01$ 
For the ANOVA analyses, we compared student perceptions between the Control group and the Good Journal Use group. However, prior to conducting these comparisons, we performed analyses that confirmed there were no significant differences in student perceptions between the three levels of Journal Use (Occasional, Frequent, Every Lesson) for students who had Intervention instructors. Thus, as with the instructor analyses, we combined those three groups into the single Good Journal Use group, resulting in a 2 (Group: Good Journal Use and Control) x 2 (Time: mid and end) ANOVA being conducted for each question (other than the eighth question for which there was no mid data; in this case a single-factor group comparison ANOVA was performed for the post-semester data). In these analyses, both factors were treated as between factors because the individual student responses were anonymous and could not be linked across time. Ns varied somewhat because some students did not complete one or the other questionnaire, or they might have left individual questions blank. However, for all eight ANOVAs (one for each 10-point rating-scale question asked of the students), there were approximately 350 student participants at mid-semester and approximately 250 at the end of the semester associated with Control group instructors ( 21 and 20 instructors, mid and post, respectively). In comparison, there were approximately 250 students associated with Good Journal Use instructors at both mid (17) and end of the semester (19). In all cases, there was a significant main effect of group, with instructors in the Good Journal Use group receiving higher student ratings than those in the Control group, although in each case the effect size was small. There were no other significant effects or interactions (see table 3). Again, note students were not informed of their instructors' group placement. 
Table 3. ANOVA main effect of Group results (means, standard errors and effect sizes) for Good Journal Use and Control groups. No other effects were significant.

\begin{tabular}{|c|c|c|c|c|c|c|}
\hline Questions & \multicolumn{2}{|l|}{ F statistic } & \multicolumn{2}{|c|}{$\begin{array}{l}\text { Good Journal Use } \\
\text { means (std error) }\end{array}$} & \multicolumn{2}{|c|}{$\begin{array}{c}\text { Control } \\
\text { means (std error) }\end{array}$} \\
\hline $\begin{array}{l}\text { Responsive to MY level of } \\
\text { achievement of learning } \\
\text { objectives }\end{array}$ & $\begin{array}{r}\mathrm{F}(1,1086)= \\
13.79, \\
\mathrm{p}<.001\end{array}$ & .01 & 8.70 & $(0.07)$ & 8.34 & $(0.07)$ \\
\hline $\begin{array}{l}\text { Responsive to level of } \\
\text { achievement of learning } \\
\text { objectives of class OVERALL }\end{array}$ & $\begin{array}{r}\mathrm{F}(1,1084)= \\
14.41 \\
\mathrm{p}<.001\end{array}$ & .01 & 8.81 & $(0.07)$ & 8.47 & $(0.06)$ \\
\hline $\begin{array}{l}\text { Responsive to MY level of } \\
\text { engagement during class }\end{array}$ & $\begin{array}{l}F(1,1057)= \\
9.99, p<.002\end{array}$ & .01 & 8.63 & $(0.08)$ & 8.30 & $(0.07)$ \\
\hline $\begin{array}{l}\text { Responsive to OVERALL level } \\
\text { of engagement during class }\end{array}$ & $\begin{array}{l}\mathrm{F}(1,1059)= \\
9.94, \mathrm{p}<.002\end{array}$ & .01 & 8.73 & $(0.07)$ & 8.43 & $(0.07)$ \\
\hline
\end{tabular}

Effective instructional techniques

$\begin{array}{lrlrll}\text { Used instructional techniques } & \mathrm{F}(1,1069)= & .01 & 8.89 & (0.09) & 8.54 \\ \text { to enhance MY learning } & \begin{array}{r}7.94, \\ \mathrm{p}<.005\end{array} & & & & \\ & \mathrm{~F}(1,1067)= & .02 & 8.59 & (0.08) & 8.18 \\ & \begin{array}{r}14.79, \\ \mathrm{p}<.001\end{array} & & & & \\ \begin{array}{l}\text { Used instructional techniques } \\ \text { to enhance learning of class } \\ \text { OVERALL }\end{array} & \mathrm{F}(1,1049)= & .01 & 8.51 & (0.09) & 8.12 \\ & \begin{array}{r}10.94, \\ \mathrm{p}<.001\end{array} & & & \end{array}$


Used instructional techniques

to enhance OVERALL level of

engagement (post only*)

$\begin{array}{rlr}\mathrm{F}(1,481)= & .02 \quad 8.37 \\ 10.53, & & \\ \mathrm{p}<.002 & & \end{array}$

7.90

${ }^{*}$ No data were collected at mid-semester for the final question regarding student perception of instructor use of techniques to enhance engagement of the class at large due to a coding error in the survey software.

\section{Goal three: Motivations and deterrents to using metacognitive instruction}

Our third goal was to better understand motivations and deterrents to instructor use of metacognitive instruction practices. Both Intervention and Control instructors reported being motivated to incorporate metacognitive instruction to enhance student learning, improve their teaching, or both. However, following their experience with the journal, Intervention instructors reported several challenges to actually implementing metacognitive instruction. Open-ended responses across the midand post-semester periods indicated the most common barrier to implementation was time. Specifically, instructors reported issues with respect to a) time to write in their journals or reflect about their classes, b) time tradeoffs in class (e.g., delivering content vs. employing alternative learning strategies), and c) general time constraints (both in and out of the classroom). When asked specifically about pre-lesson planning, a typical response was, "The amount of time allocated toward class preparation ... usually came out of hide, so spending additional time with metacognition required even more time out of hide." Similarly, approximately 30 percent of respondents reported time was also a factor for timely adjustments, such as "the challenge is in having the time to make changes during the lesson." Beyond time, there were a variety of other factors mentioned as challenges, especially for timely adjustments. Instructors reported overcoming their teaching routine was a challenge to making timely adjustments, such as "my long-term habits from teaching the same material/skills repeatedly" and "it is easy to 'get on a roll' with material that is familiar and forget to stop and 'check in' on students' understanding/learning." Others indicated identifying alternative strategies to use when they became aware of issues with student learning/engagement was a barrier: "My biggest challenge is coming up with good strategies and my comfort level in trying new things." Finally, customizing instruction for individual student needs challenged instructors: "I can't just push forward ... I have to slow down and take notice and backtrack if necessary." This assortment of instructor comments suggests a complex set of barriers to implementing metacognitive instruction, although time is clearly a key factor to address.

\section{DISCUSSION}

The results address our three goals to explore and understand 1) baseline teacher familiarity with metacognitive instruction, 2) the impact of a guided journal intervention, and 3 ) key motivations and challenges to the adoption of metacognitive instruction practices. These results show that the journal use had a positive impact on both instructors and student perceptions, but as is common in pilot studies, there are lessons learned and suggestions regarding possible modifications for future implementation and research design. We also share faculty development opportunities to increase the journal's effectiveness as a tool to support metacognition and customize its focus. 
Both Intervention and Control instructors reported significantly more baseline familiarity with and engagement in reflective teaching than metacognitive instruction. This finding was expected based on the greater prevalence of prior literature on reflective teaching practices (e.g., Hutchings and Shulman 1999; Richlin 2001) than metacognitive instruction. Not only were most of the examples focused on reflective teaching (vs. metacognitive instruction), but those examples were also often vague and did not focus specifically on student learning and engagement. Further, the majority of examples focused on awareness vs. self-regulation. Very few instructors provided examples of practices related to timely adjustments to enhance the learning of their current students (vs. adjustments for next semester) based on such awareness. This pattern of responses indicates there is a base level comfort and familiarity with awareness practices, but self-regulation, especially focused on benefiting current students, is an opportunity for targeted and intentional faculty development. Because the Intervention and Control groups started with similar levels of self-reported behaviors and familiarity, gains made by the Intervention group were more likely the result of their interaction with the journal rather than their initial levels of understanding or practice.

Interestingly, the baseline data showed no correlation between self-reported engagement in either reflective teaching or metacognitive instruction and the number of years teaching. This finding suggests engagement in these practices may not develop naturally over time, providing another clear opportunity for targeted and intentional faculty development. The significant correlation between engaging in reflective teaching and in metacognitive instruction was not a surprise given that awareness (often through reflection) underlies metacognition (combining awareness with timely self-regulation).

With regard to the study's second goal, the journal was our attempt to provide intentional faculty development of metacognitive instruction practices. We hypothesized instructors who used the journal more often would report greater engagement on three targeted practices (pre-lesson planning, in-class awareness, and consideration of timely adjustments to support student achievement of learning objectives and engagement), as well as increased confidence in their ability to support student learning and engagement, and comfort in timely self-regulation. We also hypothesized their students would report an increased sense that their instructor was responsive to and focused on their learning and engagement. Our results suggest some support for our hypotheses, but also some logistical challenges as summarized below.

The most positive results regarding instructor journal use came from the student data, while the instructor results were more mixed. Most impressively, students whose instructors reported higher levels of engagement with the journal consistently reported greater perceived levels of instructor responsiveness to their learning and engagement and use of effective instructional techniques. This relationship was stronger for those questions related to achievement of learning objectives compared to those related to student engagement. Perhaps this finding was due to the greater number of journal prompt questions that explicitly focused on identification of instructional practices to achieve the learning objectives compared to the number of journal prompt questions related to ways to keep students engaged (table 1). These student responses are even more impressive because students did not know whether their instructor was in the Intervention or the Control group, nor did they know of the Intervention Group instructor's level of engagement with the journal. The time factor (mid- versus postsemester) did not largely affect student reports of instructor behavior, suggesting that by mid-semester 
the differences in responsiveness to learning and engagement and use of effective techniques were already observable by students. Given that, ultimately, our goals as instructors should focus on student learning and engagement, it is very encouraging that using the journal was associated with positive student ratings and impressions.

The instructor data were more mixed for the second goal. The qualitative data consistently suggested positive impact from engagement with the journal. The most apparent shift occurred with respect to an increased focus on learning objectives and student engagement (rather than on content coverage) in pre-lesson planning and on in-class awareness of how students were achieving the learning objectives. In addition, there was evidence of deeper thinking about how to respond in a timely manner to observations of varied levels of student learning and engagement. In contrast, there was only one significant group difference in the quantitative data between the Intervention and the Control groups. As hypothesized, instructors in the Good Journal Use group reported greater comfort in adjusting their lessons (timely self-regulation) based on their observations of student engagement and achievement of their learning outcomes. Given that timely adjustments were the least often reported metacognitive instruction practice at the beginning of the semester (goal one), we are encouraged to find those instructors with frequent journal use were also more comfortable in making timely adjustments. This mixture of results suggests responding to our journal prompts does lead to some desired shifts in the focus of pre-lesson planning and comfort making timely adjustments, but that further refinement of our intervention and/or assessment might increase broader incorporation of metacognitive instruction practices.

With respect to the study's third goal, our results suggest a mix of motivations and challenges for engaging in metacognitive instruction. Both Intervention and Control instructors reported similar, strong motivations to engage in metacognitive instruction to enhance student learning and to improve their craft of teaching. Not surprisingly, the Intervention group reported time constraints (including pressure to cover content) were the leading deterrents. In addition, they reported prior habits and lack of awareness of alternative, evidence-based instructional practices posed strong challenges to implementing metacognitive instruction. These time constraints and habit challenges likely led to the less-than-ideal journal use reported by many of the Intervention group instructors. The intention was for instructors to complete the journal for each lesson by answering pre-lesson journal questions before class and the remaining questions after class. However, many instructors did not complete the journal for every lesson and/or answered all questions only after class, or even at the end of a block of multiple lessons. The less often that a behavior is practiced, the less likely it will become a new habit. Generally speaking, goal-directed practice or deliberate practice, in this case the practice of metacognitive instruction, requires time and focused support (Ambrose et al. 2010). Thus, it is crucial to recognize and address these deterrents. In the subsequent paragraphs we offer several suggestions to address these deterrents, including improvement of the journal prompts and ways that a journal focused on metacognitive instruction could be used as a faculty development tool.

With respect to the various deterrents, some are more easily addressed than others. A relatively simple option is for faculty developers to share alternative instructional strategies and help showcase benefits and positive outcomes of using the journal to support metacognitive instruction efforts. They could point out that, although the journals require time, they also provide a structured format for 
developing this challenging set of skills efficiently and effectively. Social support could be provided through the establishment of faculty learning communities or through one-on-one mentorship with a faculty developer. Although meeting with others would take time, there are multiple potential benefits: a) sharing of targeted, alternative instructional strategies; b) discussion of time management with respect to pre-lesson planning and perceived time pressures to cover content during lessons; and c) a more objective perspective with respect to interpretation of student engagement and learning challenges observed in the classroom. In addition, faculty developers could work with instructors using the journal prompts as a way to organize lesson planning and to scaffold productive lesson observations. Finally, a consideration for future studies is to investigate whether instructors become more efficient in using the journal over the semester, resulting in a reduction of the time pressure. For example, alternative strategies for commonly used activities can be reused in subsequent lessons, reducing the time needed to answer the journal prompts for those later lessons.

As noted above, the data are generally positive regarding the efficacy of using the journal intervention; however, for future efforts we believe there is room for improvement with respect to both the intervention (journal prompts) and its assessment (wording of the feedback questionnaires). For the wording of the intervention journal prompts, we have several suggestions. First, they could be revised so they require fewer essay length responses and more short answer responses, and/or a menu of alternate strategies for specific learning outcomes could be provided to help facilitate instructors when thinking of options (e.g., Facilitating Seven Ways of Learning by Davis and Arend 2013). Second, we could provide a greater variety of journal prompts with options focused on different aspects of lessons, thus allowing instructors to better customize their metacognition efforts. As we noted in the discussion above, most of our questions focused on identification of instructional practices to achieve the learning objectives compared to the number of journal prompt questions related to keeping students engaged. By including additional possible prompts, instructors could choose a subset of questions that best fit their needs for a particular lesson and/or their degree of comfort and maturity with metacognitive instruction. This approach would be similar to how Tanner (2012) helps guide student metacognition by offering question options for planning, monitoring, and evaluating in different learning situations. For example, rather than simply asking questions that broadly target the lesson overall, prompts could be designed to target specific aspects of a lesson, such as the crafting of learning objectives, the presentation of content, the use of a learning activity, or the choice of assessments. A third modification of the journal prompts would include questions with a clearer focus on timely adjustments rather than including adjustments for the next semester that material is taught. This "timeliness" of self-regulation (e.g., adjustments in instructional techniques) is important as it improves the learning experiences of the current group of students, not just looking ahead to another chance with a future group of students. By including question prompts focused on timely adjustments, we would also achieve better alignment with our feedback questions about instructors' likelihood to engage in timely adjustments.

With respect to future modifications of our assessment questionnaire, two of our study findings led us to believe some of the questions, as currently worded, allowed ambiguity or did not capture changes in metacognitive instruction practice as intended. First, wording issues might partially explain the lack of Group (Journal Use and Control) and Time (pre-post) differences in the ANOVA analysis of instructor engagement in the three metacognitive practices (pre-lesson planning, in-class awareness, and 
consideration of timely adjustments). More specifically, the questions as currently worded focus on the frequency of engagement (e.g., whether or not the behavior occurred at all, during half the lessons, or during all lessons) rather than the depth of engagement in the practice. For example, during pre-lesson planning, if an instructor started spending 30 minutes to select alternative, evidence-based practices rather than five minutes to jot down topics to cover, but engaged in the deeper planning behavior for approximately the same number of lessons for that reporting period as the more superficial planning in the prior reporting period, then no developmental change would be captured. Further, a focus on quality rather than quantity might help reduce the relatively high averages reported even at the beginning of the semester, which left little room for improvement (possibly a weak ceiling effect for those questions).

A related consideration is that respondents' conceptions of effective pre-lesson planning might have shifted across the semester, especially those who were in the Intervention group. Qualitative responses from Intervention instructors indicated two-thirds of them recognized a shift in their intentions of the pre-lesson planning, and several respondents specifically mentioned a shift in focus to learning objectives and student engagement. This contrast between the clear shifts reported in the qualitative data and the lack of change captured in the quantitative data for Intervention instructors suggests a need for questions focused on intentions rather than just actions.

A second study finding that leads us to propose a modification to our questionnaire wording is the significant decrease in instructor self-reported pre-lesson planning across the semester. We believe we did not effectively capture the "why" behind the responses, which made them difficult to interpret. For example, given the decrease is seen in both the Intervention and Control groups, one possible explanation is people become more efficient in pre-lesson planning over the course of the semester as routines are established. Another possibility is some courses may incorporate group projects/presentations toward the end of the course, which requires less planning on the instructor's part. Future research designed to investigate the effectiveness of journal use or other interventions to develop metacognitive instruction should ensure wording of measurement tools effectively captures and interprets developmental changes.

In addition to the limitations noted above regarding wording of the journal prompts and questionnaire, we acknowledge other potential limitations of the current study. Most prominent, the study relies on self-reported responses from both instructors and students, which might be prone to demand characteristics or impacted by participant motivations. For example, a concern might be that Intervention instructors inflated their reported engagement with the journal. However, we do not believe that is the case because the full range of journal engagement was reported (from "never" through to "every lesson"). This variation was actually fortunate because it allowed us to investigate how levels of engagement with the journal related to student perceptions of their instructors' ability to engage them and support their achievement of learning objectives, in addition to the originally planned Control vs Intervention group comparisons. If we had collected the journals, we would have been better able to reliably examine how and how often instructors engaged with the journals. We would be able to ask questions such as: What types of awareness and self-regulation are instructors engaging in? What specific contexts support more customization (changes in response to awareness)? We believe these would be great ideas for future research. For our first exploratory study, however, we made the intentional choice not to collect journals both to simplify the design and to avoid changing the nature of what was written. 
We also made an intentional choice not to ask anything of the Control group to not impact or change the instructional practices they already used. Future researchers might collect narratives of Control group pre-lesson, in-class, and post-lesson thought processes to examine the differences between the Control and Intervention groups.

Final limitations to acknowledge are that many of the instructors self-selected their condition, and all were in control of dissemination of the student feedback forms. Although random assignment would have been more ideal to control for confounds, our examination of the initial motivations to participate, years of teaching experience, and distribution of disciplinary expertise suggests Intervention and Control groups were roughly equivalent on these characteristics. Because of instructor control of dissemination of student feedback links, there were several cases for both Intervention and Control courses at both the mid- and the end-of-semester when students did not receive the feedback form links. However, we do not believe this limitation greatly impacted our study and its conclusions. While it is possible there was some systematic bias in which groups of students received the feedback forms (e.g., more engaged instructors being more likely to disseminate the feedback), it is unlikely, as Intervention group instructors who disseminated the student feedback forms reported the full range of engagement with the journals. Alternately, it is possible only the Control instructors who felt most confident disseminated the feedback forms. However, in that case, if there was still a difference in outcomes between the groups, which there was, then this would represent a minimum estimate of the impact and the full impact would be even greater. Regardless, we suggest future researchers consider a study design in which they control assignment to groups and dissemination of feedback forms.

\section{CONCLUSIONS}

The literature consistently shows metacognitive learning strategies help students learn more effectively (Dabarera, Renandya, and Zhang 2014; Isaacson and Fujita, 2006; Mynlieff et al. 2014; Negretti 2012; Thiede, Anderson, and Therriault 2003), that reflection is one key component of metacognition (Schraw 1998; Tanner 2012), and that students do not tend to engage in metacognitive learning practices without some directed guidance and support (Case and Gunstone 2002; Hogan et al. 2015). These prior findings prompted this study's efforts to help teachers engage in metacognitive instruction with a guided journal to teach more effectively for current students. The guided journal questions made metacognitive instruction practices visible and intentional. They prompted instructors to reflect on aspects of teaching that occurred prior to and in class (focusing on student engagement and achievement of the learning objectives), as well as possible self-regulation opportunities that might occur during a lesson or for future lessons.

Results from our five-institution study showed journal use had a positive impact on metacognitive instructional practices and student perceptions that teachers supported their learning. Given that Intervention and Control instructors reported similar levels of engagement with metacognitive instruction prior to our study, changes in the Intervention group are likely related to journal use. In particular, we found instructors using the guided journal reported greater comfort with adjusting lessons based on their observations of student engagement and achievement of their learning outcomes. This finding provides strong support for the efficacy of journal use given that timely adjustments were initially the least commonly reported type of metacognitive instruction practice. And, 
without knowing the level of their instructors' engagement with the journal, students rated instructors who more frequently engaged in the guided journal as significantly more responsive to their learning needs and more likely to use effective instructional strategies. These findings, showing benefits to both teachers and students, suggest a guided journal can be a tool for developing effective and customized teaching practices that support learning and engagement of current students, i.e., metacognitive instruction.

The current study found there are several challenges for instructors trying to become more metacognitive about their teaching. For example, although a large majority of our participants reported enhancing student learning was of great importance to them, many still did not fully engage in the journal effort. Barriers to using metacognitive instruction strategies from the journal included time constraints (both time for pre-lesson planning using the journal and time during class to deploy alternate strategies), prior habits, and uncertainty about alternative strategies. So, while our empirical data illustrate the value of using a guided reflection journal, the benefits of the journal are limited to those actually using it. Rich areas for future research include investigating ways of lowering barriers to journal use, using the journal as a tool to facilitate faculty development, and exploring additional techniques for developing metacognitive instruction.

\section{ACKNOWLEDGEMENTS}

We thank Dr. Tara Beziat, Auburn University at Montgomery, and Dr. Chris Was, Kent State University, who led data collection at their institutions.

Lauren Scharff is the director of scholarship of teaching and learning and a professor of behavioral sciences at the U. S. Air Force Academy (USA).

John Draeger is the director of the teaching and learning center and a professor of philosophy at SUNY Buffalo State (USA).

Sarah Robinson is an associate professor of geosciences at the U. S. Air Force Academy (USA).

Leli Pedro is an emeritus professor of nursing for the University of Colorado - Denver (USA).

Charity Peak is the regional director of academic programs, Association of College and University Educators (USA).

\section{NOTES}

1. Two intervention instructors completed the post questionnaires but didn't indicate their level of journal use. Thus, the total for "Good Journal Use" and "Insufficient Use" is only 25 rather than 27.

2. Control instructor $\mathrm{N}$ dropped from 18 to 15 because only 15 completed questions on in-class awareness.

Disclaimer: The views expressed are those of the authors and do not necessarily reflect the official policy or position of the Department of the Air Force, the Department of Defense, or the U.S. government. PA\#: USAFADF-2018-45 


\section{REFERENCES}

Ambrose, Susan A., Marsha Lovett, Michael W. Bridges, Michele DiPietro, and Marie K. Norman. 2010. How Learning Works: Seven Research-Based Principles for Smart Teaching. San Francisco: Jossey-Bass.

Bain, John D., Colleen Mills, Roy Ballantyne, and Jan Packer. 2002. "Developing Reflection on Practice Through Journal Writing: Impacts of Variations in the Focus and Level of Feedback," Teachers and Teaching 8, no. 2: 171-96. https://doi.org/10.1080/13540600220127368.

Bain, Ken. 2004. What the Best College Teachers Do. Cambridge, MA: Harvard University Press. Boyd, Josh, and Steve Boyd. 2005. "Reflect and Improve: Instructional Development Through a Teaching Journal." College Teaching 53, no. 3: 110-14. https://doi.org/10.3200/CTCH.53.3.110-114.

Brookfield, Stephen D. 2017. Becoming a Critically Reflective Teacher (2nd ed.). San Francisco: Jossey-Bass.

Case, Jennifer, and Richard Gunstone. 2002. "Metacognitive Development as a Shift in Approach to Learning: An In-Depth Study." Studies in Higher Education 2, no. 4: 459-70. https://doi.org/10.1080/0307507022000011561.

Dabarera, Carol, Willy A. Renandya, and Lawrence Jun Zhang. 2014. "The Impact of Metacognitive Scaffolding and Monitoring on Reading Comprehension." System 42: 462-73. https://doi.org/10.1016/j.system.2013.12.020.

Davis, James, and Bridget Arend. 2013. Facilitating Seven Ways of Learning. Stylus, Sterling, VA.

Dunlosky, John, and Keith W. Thiede. 2013. "Four Cornerstones of Calibration Research: Why Understanding Students' Judgments Can Improve Their Achievement." Learning and Instruction 24: 58-61. https://doi.org/10.1016/j.learninstruc.2012.05.002.

Flavell, John H. 1976. "Metacognitive Aspects of Problem Solving." In The Nature of Intelligence, edited by Lawrence B. Resnick, 231-36. Hillsdale, NJ: Earlbaum.

Garrison, D. Randy, Terry Anderson, and Walter Archer. 2000. "Critical Inquiry in a Text-Based Environment: Computer Conferencing in Higher Education." The Internet and Higher Education, 2, no. 2-3: 87-105.

Good, Jennifer M., and Patricia A. Whang. 2002. "Encouraging Reflection in Pre-Service Teachers Through Response Journals." Teacher Educator 37: 254-67. https://doi.org/10.1080/08878730209555299.

Grossman, Robert. 2008. "Structures for Facilitating Student Reflection." College Teaching, 57: 15-22. https://doi.org/10.3200/CTCH.57.1.15-22.

Hogan, Michael J., Christopher P. Dwyer, Owen M. Harney, Chris Noone, and Ronan J. Conway. 2015. "Metacognitive Skill Development and Applied Systems Science: A Framework of Metacognitive Skills, Self-Regulatory Functions and Real-World Applications." In Metacognition: Fundamentals, Applications, and Trends. 75-106. Springer International Publishing.

Huber, Mary. T., and Pat Hutchings. 2004. "Integrative Learning: Mapping the Terrain." The Academy in Transition. Association of American Colleges and Universities. Retrieved from http://files.eric.ed.gov/fulltext/ED486247.pdf.

Hutchings, Pat, and Lee S. Shulman. 1999. "The Scholarship of Teaching: New Elaborations, New Developments." Change: The Magazine of Higher Learning 3 no. 5: 10-15. http://dx.doi.org/10.1080/00091389909604218.

Isaacson, Randy M., and Frank Fujita. 2006. "Metacognitive Knowledge Monitoring and Self-Regulated Learning: Academic Success and Reflections on Learning." Journal of Scholarship of Teaching and learning 6, no. 1: 39-55. Retrieved from https://eric.ed.gov/?id=EJ854910.

Kolb, David A. 2014. Experiential Learning: Experience as The Source of Learning and Development (2nd ed.). Upper Saddle River, NJ: Pearson Education.

Korthagen, Fred, and Angelo Vasalos. 2006. "Levels in Reflection: Core Reflection as a Means to Enhance Professional Growth." Teachers and Teaching 11:47-71. https://doi.org/10.1080/1354060042000337093.

Kreber, Carolin. 2002. "Teaching Excellence, Teaching Expertise, and the Scholarship of Teaching." Innovative Higher Education 27, no. 1: 5-23. https://dx.doi.org/10.1023/A:1020464222360.

Lee, Icy. 2008. "Fostering Preservice Reflection Through Response Journal." Teacher Education Quarterly 35 (1): 117-39. Retrieved from https://files.eric.ed.gov/fulltext/EJ810661.pdf.

Leopold, Claudia, and Detlev Leutner. 2015. "Improving Students' Science Text Comprehension Through Metacognitive Self-Regulation When Applying Learning Strategies." Metacognition and learning 10, no. 3: 313-46. 
McAlpine, Lynn, Cynthia Weston, Catherine Beauchamp, C. Wiseman, and Jacinthe Beauchamp. 1999. "Building a Metacognitive Model of Reflection." Higher Education 37, no. 2: 105-31. https://doi.org/10.1023/A:1003548425626.

Mynlieff, Michelle, Anita L. Manogaran, Martin St. Maurice, and Thomas J. Eddinger. 2014. "Writing Assignments with a Metacognitive Component Enhance Learning in a Large Introductory Biology Course." CBE-Life Sciences Education 13, no. 2: 311-21. https://doi.org/10.1187/cbe.13-05-0097.

National Research Council (NRC). 2000. How People Learn: Brain, Mind, Experience, and School: Expanded Edition. Washington, DC: The National Academies Press. https://doi.org/10.17226/9853.

Negretti, Raffaella. 2012. "Metacognition in Student Academic Writing: A Longitudinal Study of Metacognitive Awareness and Its Relation to Task Perception, Self-Regulation, and Evaluation Of Performance." Written Communication 29, no. 2: 142-79. https://doi.org/10.1177/0741088312438529.Palmer, Parker. 2007. The Courage to Teach: Exploring the Inner Landscape of a Teacher's Life (2nd ed.). San Francisco: Jossey Bass.

Richlin, Laurie. 2001. "Scholarly Teaching and The Scholarship of Teaching." New Directions for Teaching and learning 86: 57-68.

Risko, Victoria J., Kathleen Roskos, and Carol Vukelich. 2002. "Prospective Teachers' Reflection: Strategies, Qualities, and Perceptions in Learning to Teach Reading." Reading Research and Instruction 41: 149-76. https://doi.org/10.1080/19388070209558363.

Scharff, Lauren, and John Draeger. 2015. "Thinking about Metacognitive Instruction." The National Teaching and learning Forum 24, no. 5 (September): 4-6. Retrieved from http://onlinelibrary.wiley.com/doi/10.1002/ntlf.2015.24.issue-5/issuetoc.

Schön, Donald A. 1987. Educating the Reflective Practitioner: Toward a New Design for Teaching and learning in The Professions. Jossey-Bass.

Schraw, Gregory. 1998. "Promoting General Metacognitive Awareness." Instructional Science 26, no. 1-2: 113-25. https://doi.org/10.1023/A:1003044231033.

Tanner, Kimberly D. 2012. "Promoting Student Metacognition." CBE-Life Sciences Education 11, no. 2: 113-20. https://doi.org/10.1187/cbe.12-03-0033.

Thiede, Keith W., Mary C. Anderson, and David Therriault. 2003. "Accuracy of Metacognitive Monitoring Affects Learning of Texts." Journal of Educational Psychology 95, no. 1: 66-73. https://doi.org/10.1037/00220663.95.1.66.

Ward, John R., and Suzanne S. McCotter. 2004. "Reflection as a Visible Outcome for Preservice Teachers." Teaching and Teacher Education 20: 243-57. https://doi.org/10.1016/j.tate.2004.02.004.

\section{(c) (i) $\$$}

Copyright for the content of articles published in Teaching \& Learning Inquiry resides with the authors, and copyright for the publication layout resides with the journal. These copyright holders have agreed that this article should be available on open access under a Creative Commons Attribution License 4.0 International (https://creativecommons.org/licenses/by-nc/4.0/). The only constraint on reproduction and distribution, and the only role for copyright in this domain, should be to give authors control over the integrity of their work and the right to be properly acknowledged and cited, and to cite Teaching \& Learning Inquiry as the original place of publication. Readers are free to share these materials - as long as appropriate credit is given, a link to the license is provided, and any changes are indicated. 